\section{Growth and Ripening of Persimmon Fruit at Controlled Temperatures during Growth Stage III}

\author{
A. Sugiura, G.H. Zheng ${ }^{1}$, and K. Yonemori \\ Laboratory of Pomology, Faculty of Agriculture, Kyoto University, \\ Sakyo-ku, Kyoto 606, Japan
}

Additional index words. Diospyros kaki, chlorophyll content, carotenoid content, firmness, sugar content

\begin{abstract}
Fruit temperature of persimmons (Diospyros kaki L. f. cv. Hiratanenashi) was regulated at a constant 14,22 , or $30 \mathrm{C}$ during growth stage III. Fruit growth and ripening were greatly accelerated at $22 \mathrm{C}$ compared with control fruit grown at ambient air temperature (range 9.3 to $28.5 \mathrm{C}$ ). At harvest (30 days after treatment), fruit kept at $22 \mathrm{C}$ was much heavier, more deeply colored, and softer than the controls. In contrast, 30C delayed the onset of rapid fruit expansion and ripening. At harvest, however, the fruit, though still green, were about the same size as tbe controls. With the exception of rapid chlorophyll degradation, 14C had little effect on fruit growth and ripening. Little difference in sugar content and composition was found between temperature treatments and controls.
\end{abstract}

Persimmon fruit have a double sigmoidal growth curve: two periods of rapid growth (stages I and III) separated by a period of slow growth (stage II). In Japan, the period of stage II coincides with the hot summer season and a prolonged summer often delays the onset of the final expansion (stage HI). Stage II has been observed to be shortened when 'Hiratanenashi', a major astringent cultivar, is grown in the northern parts of Japan. In these regions, the duration of high temperature in the summer is shorter than in southern parts, and, as a result, the total growing period for persimmon is shorter (Harada, 1985). These observations indicate that temperature may have an important role

Received for publication 2 Feb. 1990. The cost of publishing this paper was defrayed in part by the payment of page charges. Under postal regulations, this paper therefore must be hereby marked advertisement solely to indicate this fact.

'Present address: Dept. of Horticulture, Beijing Agricultural Univ., Beijing, China. in the growth and ripening of persimmon fruit. Chujo (1982) reported that a high wholetree temperature (30C) inhibited fruit growth and ripening of 'Fuyu' persimmon, a major nonastringent cultivar. The direct effects of fruit temperature on ripening have recently been demonstrated with grapes (Tomana et al., 1979a, 1979b) and satsuma mandarins

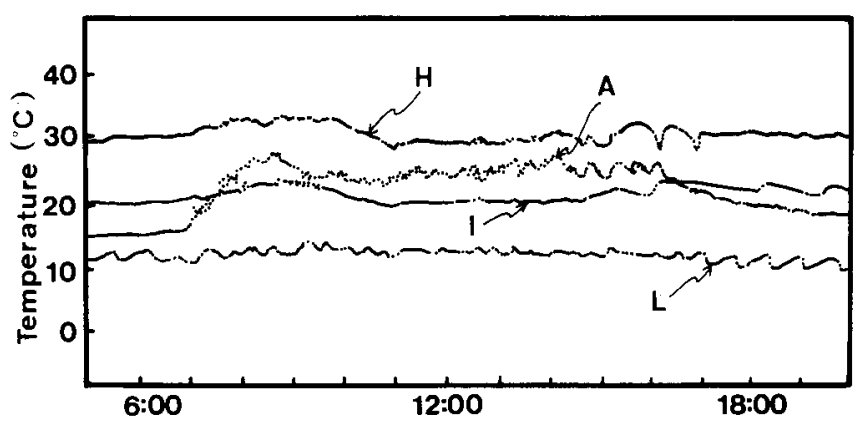

Fig. 1. Temperature fluctuation in each treatment on a given day. High $(\mathrm{H})=30 \mathrm{C}$, intermediate (I) $=22 \mathrm{C}$, low $(\mathrm{L})=14 \mathrm{C}$, and ambient $(\mathrm{A})$.
(Utsunomiya et al., 1982). The objective of this study was to determine the effect of controlled fruit temperature during stage III on growth and 'ripening of persimmons.

Six-year-old pot-grown trees of 'Hiratanenashi' persimmon were used for the experiment. They were grown outdoors and flowerthinned in mid-May 1986 to adjust the leaf : fruit ratio to $\approx 20$. Each tree bore four to seven fruits. On 20 Sept., when fruit were considered to have just entered stage III, temperature treatments were begun and continued until 20 Oct., when control fruit were judged ripe for harvest.

Temperature treatments were imposed on fruit only by means of the device described by Tomana et al. (1979a). Fruits on the tree were enclosed individually in transparent acrylic cylinders $(0.5 \mathrm{~cm}$ wall thickness, 13 $\mathrm{cm}$ inside diameter $\times 13 \mathrm{~cm}$ long) with both sides sealed with vinyl film ( $3 \mathrm{~mm}$ thick). These cylinders were fixed to limbs using strings. Their inside temperatures were regulated at $\approx 14 \mathrm{C}$ (low), 22C (intermediate), or 30C (high) day and night (Fig. 1). Vinyl tubing ( $8 \mathrm{~mm}$ in diameter), wound around the inside wall, delivered cooled or warmed water to maintain these temperatures. Control fruit were exposed to ambient temperatures (A), which gradually declined during the period of the experiment from 28.5 to 20.3C (daily maximum) and from 19.3 to 9.3C (daily minimum). Each treatment was applied to at least 20 fruits. 


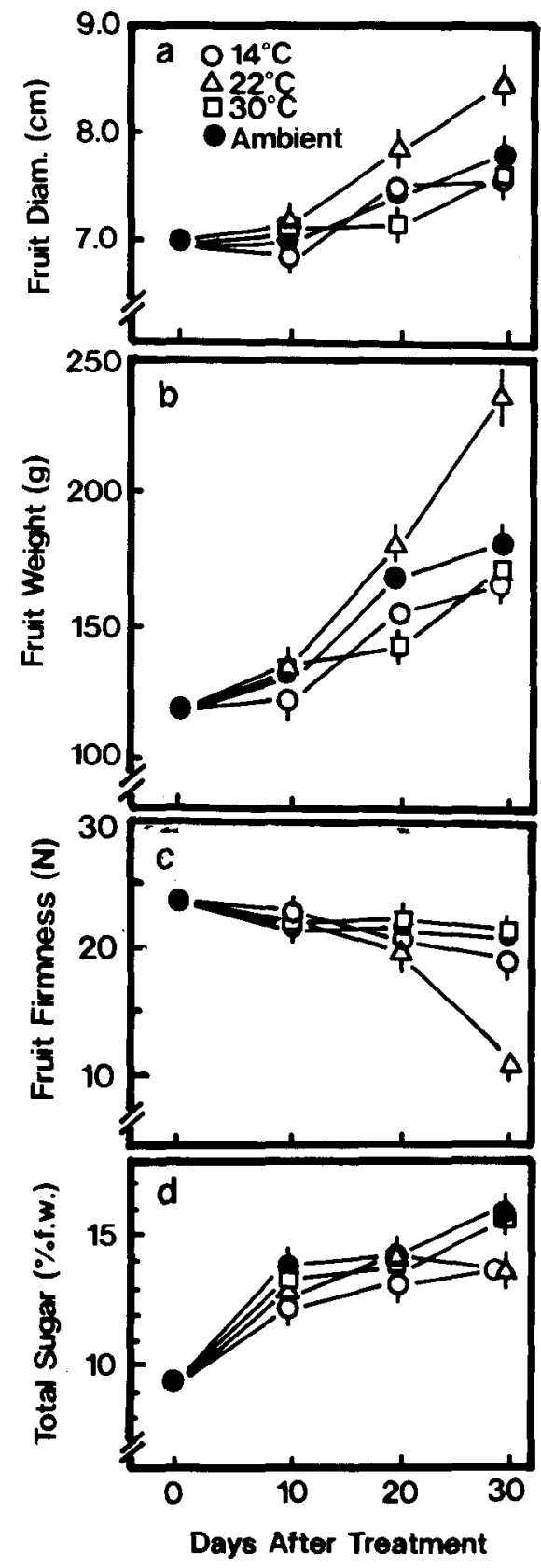

Fig. 2. Effect of fruit temperature on fruit diameter (a), weight (b), firmness (c), and total sugar (d). Vertical bars denote SEs for means of-six separate measurements.

At 10-day intervals, six fruits from each treatment were picked and fruit diameter, weight, and firmness were measured. To measure fruit firmness, resistance of the peeled flesh to crushing was determined by a pressure tester with a conical plunger tip. After these measurements, a portion of flesh and 10 pieces of skin disks $(7 \mathrm{~mm}$ in diameter) from each fruit were saved for sugar and pigment analyses. Sugar content of the flesh was analyzed by gas-liquid chromatography after silylating the methanolic extracts with a trimethylsilylating (TMS) reagent. Chlorophyll content in the skin was determined at three picking dates by Kirk's method (1968). On the last harvest date, carotenoid content, a good criterion of fruit quality, was measured by determining the absorbance at $449 \mathrm{~nm}$ of the petroleum ether fraction of methanolic extracts after saponifying with $10 \% \mathrm{KOH}$.

The intermediate temperature (22C) stimulated fruit growth in diameter and weight soon after the treatment was started (Fig. 2 $a$ and $b$ ). This promotive effect was so rapid during the treatment that final fruit size was much greater than that of the other two treatments or the control. Fruit at $22 \mathrm{C}$ also softened rapidly (Fig. 2c). Chlorophyll content in the skin decreased to a slightly lower level than in the control (Table 1). Carotenoid content on the last harvest date was highest in fruits grown at 22C (Table 1).

Fruit diameter was the smallest and weight was the lowest at 20 days for fruit held at 30C (Fig. 2 a and b). However, the final size approximated that of the control fruit. This temperature also greatly inhibited fruit coloration by maintaining higher amounts of chlorophyll and having a lower carotenoid content than control fruit or those from 22C (Table 1), but without affecting flesh firmness (Fig. 2c). Even at the final picking, the fruit was still light green. Compared with 22C, 14C had little effect on fruit growth and ripening except for coloration. Chlorophyll content was lowest at $14 \mathrm{C}$, while carotenoid content was similar to that of fruit from 30C (Table 1).

Sugar accumulation generally was similar for all fruit (Fig. 2d), except at the final harvest date, when the sugar content of fruits from 14 and $22 \mathrm{C}$ was slightly lower than that of fruit from $30 \mathrm{C}$ or from ambient temperature. Sugar composition was not influenced by fruit temperature (data not shown).

Evidence that ambient temperatures affect fruit growth and ripening is well documented. In general, relatively high temperatures are favorable for fruit growth and ripening in most fruits. The time from full bloom to maturity in a given cultivar is shorter in warm than in cool areas (Brown, 1952; Lombard et al., 1971; Winkler, 1948). However, high night temperature sometimes delays fruit growth and/or ripening (Kliewer,
1977; Kobayashi et al., 1965).

Using pot-grown 'Fuyu' persimmon trees, Chujo (1982) conducted extensive experiments to characterize the effect of day and night temperatures on fruit growth and/or ripening at growth stages I, II, and 111. His results indicated that fruit growth and ripening were most favored at 20 or $25 \mathrm{C}$ day and night, regardless of growth stage. During stage $\mathrm{H}, 30 \mathrm{C}$ was inhibitory.

In the experiment reported here, only the temperature around the fruit was regulated and the tree was exposed to ambient temperatures during stage 111. Nevertheless, the treatments had marked effects on fruit growth and ripening. We showed that an intermediate temperature (22C) favors while a higher temperature (30C) inhibits fruit growth and ripening, a result that complements Chujo's (1982) whole-tree experiments.

With 'Kyoho' grapes, Tomana et al. (1979b) exposed fruit clusters and vines separately to different temperatures during ripening and demonstrated that fruit temperature influenced fruit ripening more than did vine temperature. With vines at either 20 or $30 \mathrm{C}$, holding fruit at 15 to $20 \mathrm{C}$ enhanced anthocyanin accumulation relative to 25 to $30 \mathrm{C}$. This evidence suggests that fruit temperature itself can affect fruit physiology independently of ambient temperature, that is, tree temperature. The present result confirmed the fact with persimmons.

\section{Literature Cited}

Brown, G.D. 1952. Climate in relation to deciduous fruit production in California. V. The use of temperature records to predict the time of harvest of apricots. Proc. Amer. Hort Sci. 60:197-203.

Chujo, T. 1982. Studies on the effects of thermal conditions on the growth and quality of fruits of Fuyu kaki (in Japanese with English summary). Mere. Fat. Agr. Kagawa Univ. 37:163.

Harada, H. 1985. Studies on flower initiation and bud dormancy in annual growth cycle of Japanese persimmon (in Japanese with English summary). Tech. Bul., Dept. Hort., Faculty Agr., Shizuoka Univ. 9:1-66.

Kirk, J.T.O. 1968. Studies on the dependence of chlorophyll synthesis on protein synthesis in Euglena gracilis, together with a monogram for determination of chlorophyll concentration. Planta 78:200-207.

Kliewer, W.M. 1977. Influence of temperature, solar radiation and nitrogen on coloration and composition of Emperor grapes. Amer. J. Enol. Vitic. 28:96-103.

Kobayashi, A., H. Yukinaga, and E. Matsunaga. 1965. Studies on the thermal conditions of grapes. V. Berry growth, yield and quality of

Table 1. Effects of fruit temperature on chlorophyll and carotenoid content.

\begin{tabular}{lcccc}
\hline \hline $\begin{array}{l}\text { Fruit } \\
\text { temp }\left({ }^{\circ} \mathrm{C}\right)\end{array}$ & \multicolumn{3}{c}{ Chlorophyll content $\left(\mu \mathrm{g} /\right.$ disk $\left.^{y}\right)$} & Carotenoid content (o.d.) $)^{\mathbf{x}}$ \\
\cline { 2 - 4 } & 30 Sept. & 10 Oct. & 20 Oct. & 20 Oct. \\
\hline 14 & $0.60 \pm 0.08$ & $0.20 \pm 0.06$ & $0.09 \pm 0.15$ & $0.48 \pm 0.08$ \\
22 & $0.88 \pm 0.20$ & $0.35 \pm 0.07$ & $0.15 \pm 0.03$ & $0.88 \pm 0.06$ \\
30 & $1.35 \pm 0.06$ & $1.23 \pm 0.25$ & $0.55 \pm 0.10$ & $0.46 \pm 0.06$ \\
Ambient & $1.05 \pm 0.10$ & $0.68 \pm 0.13$ & $0.23 \pm 0.05$ & $0.60 \pm 0.10$ \\
\hline
\end{tabular}

${ }^{2}$ Data are expressed as means of six separate measurements, \pm SE.

'Seven millimeters in diameter.

${ }^{x}$ O.D. reading at $449 \mathrm{~nm}$ in $10 \mathrm{ml}$ of petroleum ether fraction from 10 disks. 
Muscat of Alexandria as affected by night temperature. J. Jpn. Soc. Hort. Sci. 34:8-14.

Lombard, P. B., C.B. Cordy, and E. Hansen. 1971.

Relation of post-bloom temperatures to 'Bartlett' pear maturation. J. Amer. Soc. Hort. Sci. 96:799-801.

Tomana, T., N. Utsunomiya, and I. Kataoka. 1979a. The effect of environmental temperatures on fruit ripening on the tree. I. The effect of temperatures around whole vines and clusters on the ripening of 'Delaware' grapes (in Japanese with English summary). Studies from Inst Hort. Kyoto Univ. 9:1-5.

Tomana, T., N. Utsunomiya, and I. Kataoka. 1979b. The effect of environmental temperatures on fruit ripening on the tree. II. The effect of temperatures around whole vines and clusters on the coloration of ' Kyoho' grapes (in Japanese with English summary). J. Jpn. Soc. Hort. Sci. 48:261-266.
Utsunomiya, N., H. Yamada, I. Kataoka, and T. Tomana. 1982. The effect of fruit temperatures on the maturation of Satsuma mandarin (Citrus unshiu Marc. ) fruits (in Japanese with English summary). J. Jpn. Soc. Hort. Sci. 51:135-141.

Winkler, A.J. 1948. Maturity tests for table grapes-The relation of heat summation to time of maturing and palatability. Proc. Amer. Soc. Hort. Sci. 51:295-298. 